\title{
Study on Cost-benefit Efficiency Evaluation of Flue-cured Tobacco Production in Guizhou Based on Improved DEA Model
}

\author{
Dong-Bing HUANG ${ }^{a,{ }^{*}}$ and Ze-Hua YING ${ }^{b}$ \\ Guizhou University of Finance and economics, Guiyang, 550025, China \\ ahuangdongbing@mail.gufe.edu.cn, b981031582@qq.com \\ ${ }^{*}$ Corresponding author
}

Keywords: Production of flue-cured tobacco, Cost-benefit, Improved DEA, Efficiency evaluation.

\begin{abstract}
The study on the cost-benefit efficiency of flue-cured tobacco production is of great significance to protecting the interests of tobacco farmers and stabilizing their enthusiasm of planting tobacco in Guizhou. According to the characteristics of flue-cured tobacco production, the evaluation system of the cost-benefit efficiency is established. By using the improved DEA model, the cost-benefit efficiency of six tobacco production areas in Guizhou is analyzed. The research results show that the model can effectively distinguish the differences among production areas and evaluate the overall production level. The model solves the defect that the traditional DEA can't distinguish the effective decision making units. This method can help to provide a theoretical basis for the rational allocation of flue-cured tobacco production resource in Guizhou. Finally, some related countermeasures and suggestions are proposed.
\end{abstract}

\section{Introduction}

Affected by the macroeconomic situation and other factors, Guizhou's tobacco production is facing increased uncertainty and complexity as well as pressure to stabilize the scale. In the meantime, the labor costs continued to rise, farmers' willingness to engage in tobacco production is on the decline, and the cost of materials for tobacco production continued to increase ${ }^{[1]}$. All of these have a great impact on the yield of tobacco production and the enthusiasm of the tobacco farmers. Therefore, the study of the cost-benefit efficiency has a strong significance to guide the production of flue-cured tobacco in Guizhou.

In recent years, scholars at home and abroad have also made some studies on the production efficiency of flue-cured tobacco. However, in previous studies, the use of the traditional DEA-C ${ }^{2} \mathrm{R}$ model exists limitations to the cost-benefit efficiency of flue-cured tobacco. In order to improve these limitations, we use the improved DEA model to achieve the ordering of all decision making units (DMU). By using this model, an evaluation model for the efficiency of flue-cured tobacco production is established. Through an empirical analysis of a city in Guizhou, it can provide a theoretical basis for improving the cost-benefits efficiency of farmers tobacco production.

\section{Evaluation Index of Cost-benefit Efficiency of Flue-cured Tobacco}

Flue-cured tobacco production can be divided into four stages: nursery stage, transplanting stage, field management stage, and bake sale stage. The latter three stages can be called planting stage. we study the cost-benefit efficiency with the input and output indicators of flue-cured tobacco production in the planting stage.

The evaluation system of cost-benefit efficiency for flue-cured tobacco includes input indicators and output indicators. The input indexes refer to the economic variables consumed by tobacco farmers in the production of flue-cured tobacco. Output indexes refer to the economic variables that produce results in the production of flue-cured tobacco. According to the principle of cost-effectiveness, the selection of indicators should be objective, measurable, feasible, and economical. And it can achieve an higher calculation accuracy. The evaluation index is shown in Table 1. 
Table 1 Evaluation index of cost-benefit efficiency of flue-cured tobacco production

\begin{tabular}{ccc}
\hline Index type & Index name & Number \\
\hline \multirow{4}{*}{ Input index } & Labor cost & $x_{1}$ \\
& Land cost & $x_{2}$ \\
Output & Material and service costs & $x_{3}$ \\
index & Yield per mu & $y_{1}$ \\
\hline
\end{tabular}

\section{Input Index}

According to the new agricultural product cost survey and accounting index system in China ${ }^{[2]}$, the total costs consist of production costs and land costs. The total cost of flue-cured tobacco refers to the cost of all the resources such as cash, physical objects, labor, and land consumed during the production of flue-cured tobacco. Production costs and land costs are the two main costs that make up the total costs. Production costs include labor costs and material and service costs. So the formula is: Total cost $=$ Material and service cost + Labor cost + Land cost. Based on the above analysis, the input index is constructed.

\section{Output Index}

According to the National Collection of Costs and Benefits of Agricultural Products in China, we need to select the main income indicators that can reflect the value of flue-cured tobacco yield. It includes flue-cured tobacco yield and value indicators. Flue-cured tobacco yield refers to the actual amount of flue-cured tobacco harvested. It is calculated according to the dry tobacco modulated. The value of flue-cured tobacco refers to the sum of income from the sale of flue-cured tobacco and the income that flue-cured tobacco can retain. Based on the above analysis, the output index is constructed.

\section{The Cost-benefit Efficiency Model of Tobacco Production}

Data envelopment analysis (DEA) method is used to study a system analysis method based on multi index input and multi index output to evaluate relative benefits among units of the same type. The advantage of DEA is that it is not necessary to determine the display expression between input and output, nor does it require any weighted assumptions. It has strong objectivity ${ }^{[3]}$. However, the traditional DEA-C ${ }^{2} \mathrm{R}$ model has two obvious limitations ${ }^{[4-5]}$ : (1) It is impossible to distinguish and order effective DMUs. It can only divide the decision unit into effective and non-effective DMU. (2) It is impractical to assign the weights of the input and output index.

In order to improve the shortcomings of the traditional DEA model, two virtual DMUs are introduced to achieve the effect of effectively distinguishing and ranking all DMUs. The two units are the optimal and the worst DMUs.

\section{DEA Basic Model}

Each flue-cured tobacco production areas is in different counties that are all in the same city of Guizhou. We call them as decision-making units (DMUs). According to the input and output indicators, the evaluation model of cost-benefit efficiency for tobacco production can be constructed. The DEA evaluation model is as follows.

There are a total of $n(n=6)$ areas. They are marked as $D M U_{j}(j=1,2, \cdots, 6) . x_{i j}$ represents the ith input index of $D M U_{j}, y_{r j}$ represents the rth input index of $D M U_{j}$. The $\mathrm{C}^{2} \mathrm{R}$ model that constitutes infinitesimal with non-Archimedes is as follows: 


$$
\begin{aligned}
& \min \left[\theta-\varepsilon\left(e^{-T} S^{-}+e^{T} S^{+}\right)\right]=V_{D} \\
& \text { s.t. }\left\{\begin{array}{l}
\sum_{j=1}^{n} x_{j} \lambda_{j}^{+s^{+}}=\theta x_{0} \\
\sum_{j=1}^{n} \lambda_{j} y_{j}^{-s^{-}}=y_{0} \\
\lambda_{j} \geq 0 \quad j=1,2, \cdots, 6 \\
s^{+} \geq 0, \quad s^{-} \geq 0
\end{array}\right.
\end{aligned}
$$

In the formula, $\theta$ is the relative efficiency index, $\mathrm{S}^{+}$and $\mathrm{S}^{-}$are slack variables, and $\lambda$ is the input variable coefficient. $e^{-T}=(1,1, \cdots, 1) \in E_{m}, e^{T}=(1,1, \cdots, 1) \in E_{s}$. Suppose the optimal solution is $\theta^{*}, \mathrm{~S}^{*+}$, $\mathrm{S}^{*-}$ and $\lambda^{*}$. The economic significance of DEA effectiveness can be explained as: (1) When $\theta^{*}=1$ and $s^{*-}=0, s^{*+}=0, D M U_{j 0}$ is effective for DEA. And the output is optimal. (2) When $\theta^{*}=1$ and $s^{*-} \neq s^{*+} \neq 0, D M U_{j 0}$ is weakly effective for DEA. We can reduce the input $\mathrm{S}^{-}$and still maintain the output unchanged, or keep the input unchanged and increase the output by $\mathrm{S}^{+}$.(3) When $\theta^{*}<1, D M U_{j 0}$ is not effective for DEA. The output can be kept unchanged by reducing the input to $\theta^{*}$ times the original input.

\section{Improved DEA Model}

To improve the above model, we introduce two virtual DMUs. That is the optimal $D M U_{n+1}$ and the worst $D M U_{n+2}$. It can effectively distinguish and sort all DMUs ${ }^{[6]}$. The input and output index values of $D M U_{n+1}$ are the minimum and maximum value of the corresponding index values from the actual DMUs. The input and output index values of $D M U_{n+2}$ are the maximum and minimum value of the corresponding index values from the actual DMUs. Finally, the DEA model of the efficiency evaluation of $n+2$ DMUs is established.

Obviously, $D M U_{n+1}$ is effective compared to other DMUs, and $\theta \equiv 1$. The $\theta$ of $D M U_{n+2}$ is necessarily the smallest. Through the DEA model of $n+2$ DMUs, we can sort them from large to small.

\section{Case}

\section{Analysis of Data by DEA Basic Model}

Data sources: Taking the six areas of a city in Guizhou as the research objects, and collecting their input and output data of tobacco production in each area. Using the DEA basic model and calculating by deap2.1 software, we can get the cost-benefit efficiency values of DMUs and their rankings, as shown in Table 2.

Table 2 Measure value of cost-benefit efficiency of flue-cured tobacco production in each area of a city

\begin{tabular}{ccc|ccc}
\hline DMU & Cost-benefit Efficiency & Rank & DMU & Cost-benefit Efficiency & Rank \\
\hline$D M U_{1}$ & 1.000 & 1 & $D M U_{4}$ & 1.000 & 1 \\
$D M U_{2}$ & 1.000 & 1 & $D M U_{5}$ & 0.978 & 5 \\
$D M U_{3}$ & 0.999 & 4 & $D M U_{6}$ & 0.798 & 6 \\
\hline
\end{tabular}

We can see from Table 2 that their cost-benefit efficiency values in each area is relatively high. Their input costs and output scales have reached a high level of production. There are 3 areas with an efficiency value of 1 . They are effective for DEA and at the best level of cost-effectiveness. The efficiency values of other three areas are not effective. The lowest efficiency value of $D M U_{6}$ is 0.798 . It means that this area has great room for improvement in cost-effectiveness. It should be pointed out that the efficiency of areas 
with the same value are still different. However, the DEA basic model cannot further evaluate and compare the efficiency of areas.

\section{Analysis of Data by Improved DEA Model}

Based on the improved DEA model, the cost-effectiveness efficiency is measured. The efficiency value and ranking of cost-benefit were obtained, as shown in Table 3.

Table 3 Cost-benefit efficiency of flue-cured tobacco production in each area

\begin{tabular}{lcccc}
\hline DMU & Cost-benefit efficiency & Scale efficiency & Returns to scale & Rank \\
\hline$D M U_{1}$ & 0.781 & 0.781 & $\uparrow$ & 5 \\
$D M U_{2}$ & 0.964 & 0.964 & $\uparrow$ & 2 \\
$D M U_{3}$ & 0.769 & 1.000 & - & 6 \\
$D M U_{4}$ & 0.871 & 0.943 & $\uparrow$ & 3 \\
$D M U_{5}$ & 0.844 & 0.940 & $\uparrow$ & 4 \\
$D M U_{6}$ & 0.577 & 0.577 & $\uparrow$ & 7 \\
$D M U_{7}$ & 1.000 & 1.000 & - & 1 \\
$D M U_{8}$ & 0.444 & 0.577 & $\uparrow$ & 8 \\
\hline
\end{tabular}

As can be seen from Table 3, the efficiency of the virtual optimal $D M U_{7}$ is 1 . It ranks first and achieves the best level of efficiency. The efficiency of the virtual worst $D M U_{8}$ is 0.444 , which is ranked last. There is no DMU with the same efficiency. Moreover, the original DMU which is effective changes to non-effective. It shows that the introduction of two virtual DMUs can effectively evaluate and rank the efficiency of all areas, and solve the problem that the DMUs achieve the same best scale efficiency and technical efficiency so that they cannot be distinguished.

$D M U_{2}$ is the highest efficiency except the virtual DMU. The efficiency is 0.964 , which is very close to 1 . It shows that its cost-benefit efficiency has been at the leading position in the tobacco production industry in the city. The lowest efficiency is $D M U_{6}$ whose efficiency value is 0.577 . This means that there is a big gap between $D M U_{6}$ and other areas. We need to make adjustments to the input and output of its flue-cured tobacco production. On the whole, it further shows that the distribution of the cost-benefit efficiency is unbalanced for the city. And the average value of the efficiency is 0.781 , which is a low level of average efficiency. The overall efficiency needs further improvement. In addition, the scale benefits can be used to reflect the scale effectiveness of DMUs. After calculations, we find that only the scale returns of $\mathrm{DMU}_{3}$ is the best, and others are in a state of increasing. It shows that other areas should increase their input appropriately to bring about higher output.

\section{Conclusion}

By using the improved DEA model, we analyzed the gap among the cost-benefit efficiency of flue-cured tobacco production areas in the city of Guizhou. It can be concluded that the city needs to be more inclined to invest $D M U_{6}$ so that its cost-benefit efficiency can reach an average level. Ultimately, the city's cost-effectiveness distribution is more evenly distributed. In fact, It is also necessary to consider many other factors such as production processes and production organizations in the production of flue-cured tobacco. But this will make the study more complicated.

The following countermeasures and suggestions have been put forward for cost reduction of flue-cured tobacco production. (1) optimize the organizational form of flue-cured tobacco planting. Compared with other organizational forms, productive cooperatives have the largest reduction in production costs of flue-cured tobacco. But this form of organization is not yet mature. It needs the joint efforts of tobacco farmers and tobacco business enterprises. (2) Efforts to promote land circulation. We need to strive to form a flue-cured tobacco planting mode with large planters, family farms, and cooperatives as the mainstay, and gradually eliminate small-scale planting forms. It can improve land-use efficiency to achieve scaled-up results. (3) Increase the degree of specialization of tobacco leaf production. The production of flue-cured tobacco is a complicated task. The use of specialized teams can effectively 
reduce the use of labo and the requirements of tobacco farmers to master all the technologies. tobacco farmers can get real benefits in the process of specialization. (4) Make a reasonable purchase price of tobacco. Scientific evaluation of tobacco planting costs can promote the establishment of a reasonable price mechanism. Farmers' profits can get increasing, and their enthusiasm for growing tobacco can be increasing.

\section{Acknowledgement}

This work is financially supported by the Guizhou Science and Technology Department (Research on precision poverty alleviation mechanism based on big data private cloud[2016]1512-4).

\section{References}

[1] Yin Wang, Hong Yan and Dongbing Huang, Research on production cost index of flue-cured tobacco, Chinese and foreign exchange. 29 (2016).

[2] Chuanbin Cui, Research on the efficiency of China's tobacco agricultural production, Diss., Northwestern University, 2010.

[3] Dong Du, Qinghua Pang and Wu Yan, Modern comprehensive evaluation method and case selection, third ed., Tsinghua University press, 2015.

[4] Adler, Nicole, L. Friedman and Z. Sinuany-Stern, Review of ranking methods in the data envelopment analysis context, European Journal of Operational Research. 140.2(2007):249-265.

[5] Angulo-Meza, Lidia and M. P. E. Lins, Review of methods for increasing discrimination in data envelopment analysis, Annals of Operations Research. 116.1-4(2002):225-242.

[6] Bing Sun and Daming Zhou, Evaluation and empirical research on the status of independent innovation of equipment manufacturing enterprises based on improved DEA, Science and technology progress and Countermeasures. 28.15 (2011): 106-110. 